\title{
Profissão docente: uma análise sistêmico-funcional do discurso de professores sobre sua prática
}

\author{
Suzana de Carvalho Barroso Azevedo \\ CEFET-RJ / Pontifícia Universidade Católica do Rio de Janeiro - PUC-Rio
}

\begin{abstract}
Resumo
Esta pesquisa tem por objetivo entender como professores em atuação na educação básica da rede pública constroem sua prática profissional, enfocando as avaliações e posicionamentos que surgem em seus discursos sobre a atividade docente. $\mathrm{O}$ estudo está inserido no domínio da Linguística Aplicada (MOITA LOPES, 2006) e dos estudos educacionais sobre o trabalho docente (GIROUX, 1997; TARDIF; LESSARD, 2013). Como aporte teórico, utilizo os princípios da Linguística Sistêmico-Funcional (HALLIDAY; MATTHIESSEN, 2004) e do Sistema de Avaliatividade (MARTIN, 2001; MARTIN; WHITE, 2005), perspectivas que concebem a linguagem como orientada para o uso e dotada de recursos para que usuários se posicionem ideologicamente. Para tanto, considero os dados gerados em um grupo focal (GATTI, 2012) entre três professores que atuam na educação básica em escolas públicas no estado do Rio de Janeiro. As análises sugerem um posicionamento afetivo por parte dos participantes diante de sua profissão.
\end{abstract}

Palavras-Chave: professores, prática profissional, linguística aplicada, trabalho docente, linguística sistêmico-funcional, sistema da avaliatividade

\begin{abstract}
The aim of this study is to investigate how teachers who work in primary and secondary public education construct their professional practice, focusing on evaluations and positionings which come up in their discourse about the teaching activity. The study is embedded in the domain of Applied Linguistics (MOITA LOPES, 2006) and educational studies about teachers' work (GIROUX, 1997; TARDIF, 2013). As a theoretical linguistic framework, the analyses are based on the principles of Systemic Functional Linguistics (HALLIDAY; MATTHIESSEN, 2004) and the Appraisal System (MARTIN, 2001; MARTIN; WHITE, 2005), perspectives which conceive language as oriented to use and having resources for the users to adopt ideological stances. Therefore, a focus group (GATTI, 2012) was conducted with three teachers who work in primary and secondary public schools in Rio de Janeiro. Analyses indicate that participants adopt an affective positioning in relation to their practices.
\end{abstract}

Keywords: teachers, professional practice, applied linguistics, teachers' work, systemic functional linguistics, appraisal system 


\section{CONSIDERAÇÕES INICIAIS}

O entendimento da profissão docente a partir da observação do discurso de professores pode iluminar questões sobre a escola, a vida em sala de aula e o panorama educacional em geral com base na aproximação entre elementos teóricos de análise e vivências práticas. Trata-se, então, de um movimento de explorar as condições, tensões e dilemas que permeiam esta profissão entendendo os professores como agentes responsáveis pela produção de conhecimento sobre sua prática.

Sendo assim, a pesquisa elaborada para este artigo tem por objetivo compreender como professores que atuam na educação básica da rede pública constroem sua prática profissional, focalizando as avaliações e posicionamentos que surgem em seus discursos em relação aos diversos assuntos que perpassam a atividade docente.

O desenvolvimento desta pesquisa conta com a articulação de algumas áreas do conhecimento que se complementam a fim de proporcionar um panorama mais amplo e que considere o fenômeno estudado em sua pluralidade. Em primeiro lugar, o trabalho se insere no domínio da Linguística Aplicada (LA) que, considerando sua orientação interdisciplinar e política, suscitam a interface com os estudos educacionais sobre o trabalho docente.

Com base neste cenário teórico, proponho a utilização da Linguística SistêmicoFuncional (LSF) (HALLIDAY; MATTHIESSEN, 2004) e do Sistema de Avaliatividade (SA) (MARTIN, 2001; MARTIN; WHITE, 2005) como arcabouços teóricometodológicos que norteiam a visão de linguagem e análise do discurso nesta pesquisa. De maneira resumida, a LSF entende a linguagem como uma rede de possibilidades orientada para o uso, enquanto que o SA estuda a atitude dos usuários da língua diante dos fenômenos do mundo bem como os recursos que utilizam para se posicionar ideologicamente em seu discurso.

Tomando por base a perspectiva de análise do discurso advinda deste arcabouço teórico, que propõe a interface entre a análise da gramática e a análise da atividade social, considero os dados gerados em um grupo focal (GATTI, 2012) entre três professores que atuam na educação básica em escolas públicas no estado do Rio de Janeiro. Nesta interação, gravada em áudio e transcrita, foram selecionados fragmentos 
para a análise e identificados, por meio dos recursos da LSF e do SA, posicionamentos e avaliações dos participantes acerca de sua prática profissional.

Com vistas a discutir e compreender as questões recém expostas, este artigo está organizado textualmente em sete seções. Inicialmente, após esta introdução, faço um apanhado das concepções teóricas que embasam esta pesquisa, como a LA e os estudos educacionais sobre o trabalho docente. Em seguida, será feita uma revisão da LSF e do SA, escolhas que sustentam a visão de linguagem do trabalham e informam a análise dos dados. A seção sobre os aspectos metodológicos oferece uma descrição sobre o contexto de pesquisa, participantes, procedimentos e geração dos dados e condução da análise. A seção a seguir propõe a análise dos dados e uma discussão possibilitada pelos entendimentos ali gerados. A última seção apresenta uma retomada dos pontos fundamentais do trabalho bem como suas contribuições.

\section{ONDE ESTAMOS: LINGUAGEM E EDUCAÇÃO}

A fim de situar este trabalho em termos conceituais e teóricos, exponho, nesta seção, os princípios da LA bem como algumas noções advindas dos estudos educacionais sobre o trabalho docente. Como será possível perceber nas linhas a seguir, a articulação entre a LA, sobretudo em seu caráter interdisciplinar e político, e as pesquisas sobre a profissão docente oferecem um pano de fundo profícuo para o desenvolvimento da análise dos dados.

\section{Linguística Aplicada}

Este trabalho se insere no domínio da LA, área cujos estudos objetivam "criar inteligibilidade sobre problemas sociais em que a linguagem tem um papel central" (MOITA LOPES, 2006, p. 14). A concepção mais atual de LA enfoca a investigação de questões de uso da linguagem sob um viés interdisciplinar, político e co-participativo, isto é, estimula o diálogo com outras teorias e disciplinas das ciências humanas e sociais, além de propor uma problematização da vida social que promova a participação e ascensão de grupos socialmente marginalizados (MOITA LOPES, 2006).

Em relação ao perfil interdisciplinar da LA, entende-se que as várias áreas do conhecimento humano podem fornecer subsídios teóricos relevantes para que questões de uso da linguagem sejam analisadas na prática. $\mathrm{O}$ recurso da interdisciplinaridade 
possibilita uma visão dos fenômenos por diferentes ângulos, colaborando, assim, para um entendimento mais completo dos seus variados aspectos. Nesse contexto, vale ressaltar uma tendência contemporânea em LA que prioriza uma pesquisa ainda mais focada em situações reais e que seja capaz não apenas de teorizar sobre a vida social como também de compreendê-la a partir de um novo olhar. Moita Lopes (2006) ressalta a necessidade de ouvir as "vozes do Sul", ou seja, de considerar aqueles que de fato vivenciam as práticas sociais e tentar compreender a vida social a partir da perspectiva dessas vozes marginais. Desta maneira, a ideia de que a pesquisa deve possuir uma agenda política está incorporada à LA atual, haja vista sua tendência questionadora de modelos hegemônicos bem como sua preocupação com a emancipação daqueles cujas vozes foram historicamente silenciadas.

\section{O Trabalho Docente}

As pesquisas acerca de questões relativas ao ensino cresceram substancialmente após a Segunda Guerra Mundial, quando a escolarização passou a ser vista como um processo fundamental na sociedade (TARDIF; LESSARD, 2013). Inicialmente, as pesquisas e reformas educacionais estavam concentradas na aprendizagem e visavam à melhoria das condições de estudo dos alunos em termos de igualdade, democratização do ensino e integração de pessoas com dificuldades. Devido a um desconforto geral com a escola e à insatisfação de professores com a falta de reconhecimento social pela sua profissão, mais recentemente, o foco dos estudos educacionais direcionou-se também para as condições de trabalho dos professores, formação e profissionalização (TARDIF et al., 1998 apud TARDIF; LESSARD, 2013). Sendo assim, este trabalho pretende dar corpo às pesquisas sobre o trabalho docente na medida em que se interessa pela forma como esses profissionais constroem e se posicionam discursivamente em relação à sua prática.

Nesse contexto, para fins de localização teórica, cumpre ressaltar que entendo a docência como uma profissão das interações humanas, isto é, uma ocupação em que "as relações entre os trabalhadores e as pessoas constituem o processo de trabalho, o qual consiste em manter, mudar ou melhorar a situação humana das pessoas, inclusive as pessoas elas próprias" (TARDIF; LESSARD, 2013, p. 20). O fato de as pessoas constituírem-se como a "matéria-prima", por assim dizer, do trabalho tem implicações

\footnotetext{
${ }^{1}$ Termo utilizado por Tardif \& Lessard (2013).
} 
de diversas naturezas, como por exemplo, a presença de relações constantemente definidas e mediadas pela linguagem. A linguagem funciona não só como elemento central na construção dos conhecimentos escolares de cunho conteudista como também no estabelecimento de relações sociais entre os atores que participam do processo de ensino e aprendizagem.

Ademais, o caráter interativo e humano da docência envolve a questão afetiva que permeia as relações entre professores e alunos. De acordo com Tardif \& Lessard (2013), o amor configura-se como necessário ou desejável para orientar a docência, de modo que a função do ensino dificilmente será exercida sem tal engajamento afetivo. Como se pode perceber, uma profissão interativa como a docência possui especificidades que vão para além da técnica e da execução objetiva do trabalho, haja vista a complexidade característica do ser humano.

Conforme mencionado anteriormente, pesquisas sobre o trabalho docente têm se proliferado nos últimos anos dando origem a uma rica e diversa literatura acerca do tema. Diante desta realidade, questiona-se como fazer uma análise em torno da docência que de fato privilegie os saberes, práticas, representações e crenças dos professores. Segundo Tardif \& Lessard (2013, p 36), o primeiro passo é "fazer uma critica resoluta das visões normativas e moralizantes da docência, que se interessam antes de tudo pelo que os professores deveriam ou não fazer, deixando de lado o que eles realmente são e fazem $^{2}$ ". Entende-se, então, que a docência deve ser observada a partir da descrição e análise das atividades práticas de trabalho, nos locais onde são desenvolvidas e com base na visão daqueles que vivenciam o processo. Esse novo paradigma requer um deslocamento do olhar das estruturas para o processo, isto é, uma substituição da análise "pelo alto" pela análise das práticas que contribuem para a manutenção e transformação do ensino e da escolarização (TARDIF; LESSARD, 2013).

Além deste ângulo de visão oportunizar a compreensão das questões com base em seus contextos concretos, ele também se alinha ao entendimento do professor como um profissional capaz de analisar e teorizar sobre sua prática bem como implementar mudanças baseado em sua experiência diária, ou, nas palavras de Giroux (1997), como um intelectual transformador. Segundo esta perspectiva, o docente não deve ser visto como um simples aplicador de técnicas elaboradas por outros profissionais e sim como

\footnotetext{
${ }^{2}$ Grifos conforme o original.
} 
aquele que pensa sobre seu trabalho e é o responsável por construir uma percepção sobre o que é a docência, a escola e o processo educativo.

Com o intuito de resumir e relacionar os assuntos tratados até então, destaco que este trabalho se alicerça nos conceitos fundamentais da pesquisa recente em LA, sobretudo no que se refere à necessidade de fabricar a vida social por meio de uma ótica não hegemônica e à interdisciplinaridade. Nesse sentido, enfoco o discurso do professor sobre sua prática, consubstanciando a ideia da análise a partir das vozes dos praticantes, normalmente silenciadas por instituições dominantes. Em relação ao recorte interdisciplinar, pode-se afirmar que este abrange a interface entre educação e linguística, o que inclui os estudos educacionais sobre o trabalho docente e a LSF como viés teórico-metodológico de linguagem, assunto que será articulado nas seções a seguir.

\section{FUNDAMENTAÇÃO TEÓRICA}

\section{A Linguística Sistêmico-Funcional}

A LSF é uma teoria que concebe a linguagem como um sistema potencial de significados no qual os usuários fazem escolhas para veicular significados determinados em contextos específicos. Cada uma dessas escolhas gera uma série de novas opções que se especificam em redes de possibilidades que estão ali disponíveis para serem selecionadas de acordo com os sentidos que se deseja construir.

De acordo com Halliday \& Matthiessen (2004), esta é uma teoria sociossemiótica, entendendo a semiótica como o estudo dos sistemas de significados, dentre os quais a linguagem é o mais fundamental e vasto da cultura humana. A LSF também é uma teoria social, na medida em que entende a língua como naturalmente orientada para o uso, sendo sua existência condicionada às necessidades de comunicação das pessoas. Desta maneira, para a LSF não existe língua desconectada do uso, isto é, a linguagem é social e ela só ocorre se estiver imbricada na sociedade.

Nesse contexto, a descrição de uma língua não pode se pautar somente no conhecimento do sistema e suas estruturas linguísticas e sim no uso que fazemos deles para agir na vida social. Com vistas a entender como as pessoas utilizam a língua para desempenhar funções na vida social e expressar significados, os estudos com base na LSF lidam com o texto como unidade de análise. De acordo com esta teoria, os textos 
são unidades semânticas realizadas através de fraseados $^{3}$, os quais são explicados pela gramática cuja orientação é funcional e semântica, isto é, deve estar vinculada ao uso. Desta maneira, a gramática do discurso deve ter um lugar central na análise de textos, além de ter categorias que de fato reflitam os padrões semânticos.

A LSF, então, encontra respaldo no sistema + texto de maneira interdependente para realizar suas análises. Esses dois elementos estão relacionados de tal forma que "qualquer pessoa que entenda o texto, o faz porque conhece o sistema" (HALLIDAY, 1994, p. xxii). O autor acrescenta que "uma análise do discurso que não está baseada na gramática, não é uma análise e sim um simples comentário de um texto" (HALLIDAY, 1994, p. xvi). Por esta teoria, texto e contexto são aspectos do mesmo processo uma vez que o contexto significa um outro texto que acompanha o texto principal, incluindo acontecimentos não verbais e o ambiente geral no qual se desenrola, de modo a estabelecer uma ponte entre o texto e a situação em que ele ocorre (HALLIDAY; HASAN, 1989). Halliday \& Matthiessen (2004) identificam o contexto de cultura e o contexto de situação, detalhados a seguir.

Primeiramente e de forma mais geral, temos o contexto de cultura que circunda o texto e está relacionado às formas como diferentes culturas utilizam a língua. Existem diversas maneiras de expressar significados, por exemplo, formas de tratamento e polidez que variam de acordo com as culturas. Logo, qualquer tipo de interação linguística não consiste apenas em sons e sinais trocados, mas envolve todo o contexto histórico daquela cultura e dos participantes envolvidos naquela prática. A interpretação do significado depende da realidade cultural dos falantes.

Além do contexto cultural, existe o contexto de situação, que consiste nas variações de linguagem mais particulares dentro de cada cultura, conforme o momento em que ocorrem. $\mathrm{O}$ contexto de situação corresponde às características extralinguísticas dos textos que se realizam a partir dos padrões utilizados pelos falantes, consciente ou inconscientemente, para construir textos nas diferentes variedades (BUTT et al, 1998). Sobre o contexto de situação, vale ressaltar ainda que a configuração contextual é formada por três elementos que determinam as escolhas linguísticas que, por sua vez, criam significados distintos. São eles: campo, relações e modo. Tais elementos estão relacionados às Metafunções da linguagem que também serão expostas nesta seção.

\footnotetext{
${ }^{3}$ Halliday (1994) originalmente utiliza o termo wording e o define como o meio através do qual os significados são realizados nas frases, isto é, seqüências gramaticais ou sintagmas que contêm itens lexicais e gramaticais. A gramática é uma teoria de fraseados.
} 
O campo (field) corresponde ao evento que está ocorrendo, à natureza da ação social, seus objetivos a longo e curto prazo. Já as relações (tenor) correspondem à natureza dos participantes, seu status, papéis e a forma como estão relacionados, por exemplo, falante e ouvinte, escritor e leitor. Por fim, temos o modo (mode), que consiste no papel da linguagem e organização do texto, isto é, o que os participantes esperam que a linguagem faça por eles naquela situação.

Como foi dito anteriormente, a linguagem é utilizada para um determinado fim, ou seja, ela serve para satisfazer as necessidades de expressão daqueles que se utilizam dela para se comunicar. Halliday \& Matthiessen (2004) entendem, então, que a linguagem deve ser explicada a partir das suas funções na vida social e identificam três funções principais, a saber: Ideacional, Textual e Interpessoal. Estas são denominadas de Metafunções por seu caráter central na forma como a linguagem se desenvolveu ao longo dos tempos e, consequentemente, por seu papel primordial na teoria em questão. Cada uma delas está relacionada aos elementos do contexto descritos acima e a um sistema de representação específico que será detalhado adiante. A relação entre essas variáveis está esquematizada na figura abaixo.

\begin{tabular}{|c|c|c|}
\hline Elemento do contexto & Metafunção da linguagem & Sistema de representação \\
\hline Campo & Ideacional / Experiencial & Transitividade \\
\hline Relações & Interpessoal & Modo \\
\hline Modo & Textual & Tema e Rema \\
\hline
\end{tabular}

A Metafunção Ideacional refere-se à possibilidade que a linguagem oferece de falar sobre o mundo, representá-lo, transmitir e expressar ideias. Vê a oração como representação e seu significado é a expressão de algum tipo de evento, ação, estado ou outro fenômeno do mundo real (HALLIDAY; HASAN, 1989). A linguagem tem a capacidade de criar significados experienciais e a oração é o meio pelo qual isso se materializa uma vez que ela tem a finalidade de expressar os processos que controlam e denotam a realidade. Um Processo ${ }^{4}$ subentende Participantes, Circunstâncias e Processos (geralmente representados por verbos). Halliday identifica três tipos

\footnotetext{
${ }^{4}$ Os termos de gramática sistêmico funcional em português foram retirados da lista aprovada pelas equipes de investigação da FLUL, do projeto DIRECT da PUC-SP, e por outros pesquisadores da LSF.
} 
principais de Processos (Materiais, Mentais e Relacionais) e três outros tipos secundários (Verbais, Comportamentais e Existenciais) que se encontram nos limites entre os três principais.

A Metafunção Textual é responsável por organizar estruturalmente as outras duas funções de modo que a mensagem seja reconhecível para o receptor. O que de fato organiza a oração como mensagem é a sua estrutura temática e, para tal, um elemento é enunciado como Tema tornando-se o ponto de partida da mensagem e a base a partir da qual a mensagem se desenrola. O Tema se combina com o restante da oração (denominado Rema).

Por fim, a Metafunção Interpessoal está relacionada à característica que a linguagem tem de ser utilizada para estabelecer trocas e relações entre falante e ouvinte, cujos papéis são definidos durante a interação. Essa função é realizada principalmente a partir do sistema de Modo, composto pelo Sujeito (elemento o qual o falante ou escritor quer responsabilizar pela validade da proposição da oração) + Finito (elemento que denota tempo e polaridade).

Esta última Metafunção é primordial para a análise dos dados desta pesquisa, uma vez que dela se desenvolve o Sistema de Avaliatividade, que organiza e descreve a gama de recursos avaliativos potencialmente disponíveis na língua. É essa extensão da Metafunção Interpessoal que descrevo no item a seguir.

\section{O Sistema de Avaliatividade}

A sistematização dos recursos linguísticos que interlocutores utilizam para fazer avaliações sobre o mundo à sua volta e assim se posicionarem diante dos fenômenos que ali circulam começou a ser feita a partir dos anos 90 por um grupo de pesquisadores da Universidade de Sidney. O fruto das pesquisas desenvolvidas deu origem ao Sistema de Avaliatividade, cujo objetivo é estudar a atitude dos usuários da língua diante dos fenômenos do mundo, tendo como foco a maneira como expressam, negociam e naturalizam posicionamentos ideológicos (WHITE, 2001).

Este sistema está dividido em três subsistemas ou domínios semânticos de acordo com os tipos de significados selecionados pelos interlocutores para estabelecerem seus posicionamentos discursivos: Atitude, Engajamento e Gradação. Atitude são os recursos utilizados para expressar emoções, julgar comportamentos e avaliar processos, objetos e fenômenos. Esse subsistema é especialmente relevante para 
essa pesquisa e será destrinchado a seguir. O Engajamento refere-se aos recursos empregados para expor e negociar posições carregadas de conteúdo ideológico. Já a Gradação relaciona-se com os recursos utilizados para graduar o impacto, força ou volume do que é dito ou escrito (WHITE, 2001). Sendo a Atitude o subsistema que informará a análise de dados deste trabalho, destaco que este se divide nas categorias Afeto, Julgamento e Apreciação.

O Afeto diz respeito às reações e inclinações emocionais, como, por exemplo, nos termos destacados em: Eu amo este filme, Eu olhei para ele alegremente, Estou feliz hoje, O pavor tomou conta de todos. Ao utilizar o recurso do Afeto, o usuário da língua demonstra como um determinado fenômeno o afetou emocionalmente e, ao mesmo tempo, convida o seu interlocutor a compartilhar com ele o mesmo posicionamento.

O recurso do Julgamento é utilizado para avaliar o comportamento humano a partir de uma série de normas institucionalizadas culturalmente e, por esse motivo, as análises neste domínio serão marcadamente atreladas ao contexto de cultura. De acordo com Martin \& White (2005), esta categoria se divide entre Sanção Social e Estima Social. O primeiro ocorre quando o Julgamento prevê consequências legais ou morais, isto é, quando o comportamento sob avaliação é passível de elogio ou condenação. Já no segundo caso, o Julgamento não motiva sanções legais, mas o comportamento dos indivíduos está sujeito à admiração ou crítica.

A categoria da Apreciação é concernente à avaliação de fenômenos, objetos e processos. Também está estruturada em subtipos, a saber: reação, composição e valor. Reação refere-se à maneira como um conteúdo atinge uma pessoa emocionalmente em relação ao seu impacto ou valor. A composição relaciona-se com a avaliação de acordo com a proporcionalidade ou equilíbrio de algo. Já o valor é a importância social atribuída aos processos ou produtos (MARTIN, 2000).

O sistema Atitude dentro do Sistema de Avaliatividade é crucial para o desenvolvimento deste trabalho, pois reúne as categorias de análise Afeto, Julgamento e Apreciação, que podem trazer entendimentos sobre os posicionamentos dos docentes participantes em relação à sua prática. O estudo das falas desses professores está dentro da perspectiva de Análise do Discurso (AD) da LSF, que sugere a interface entre a análise da gramática e a análise da atividade social. Conforme Martin \& Rose (2003), os textos vão além das orações, porém estão aquém da cultura, de maneira que a $\mathrm{AD}$ emprega as ferramentas gramaticais com vistas a identificar funções dos elementos 
textuais assim como leva em consideração os conceitos advindos das ciências sociais a fim de compreender como e porque os textos constroem determinados sentidos em uma cultura específica.

\section{ASPECTOS METODOLÓGICOS}

Esta pesquisa está inserida em um paradigma qualitativo (DENZIN \& LINCOLN, 2006), que busca compreender questões a partir do significado que as pessoas atribuem a elas, sem buscar generalizações fornecidas por dados numéricos e estatísticos e sim entendimentos da realidade social a partir do olhar dos indivíduos nela envolvidos. As características da pesquisa qualitativa vão ao encontro dos fundamentos que orientam o uso de grupos focais, técnica de pesquisa utilizada para a geração de dados desta investigação, como será esclarecido adiante.

Um grupo focal é um encontro de pessoas para uma discussão que objetiva ouvir e gerar informações sobre como esses indivíduos se sentem e o que pensam sobre um determinado assunto (Krueger \& Casey, 2000). Essa ferramenta de pesquisa tem como princípio teórico norteador o fato de que as pessoas tomam consciência de si e de seus pensamentos quando têm contato com a opinião do outro. Nesse sentido, Gatti (2012, p. 9) afirma que "o grupo focal permite fazer emergir uma multiplicidade de pontos de vista e processos emocionais, pelo próprio contexto de interação criado, permitindo a captação de significados que, com outros meios, poderiam ser difíceis de se manifestar". Além disso, a autora acrescenta que o grupo focal beneficia os participantes na medida em que amplia "suas perspectivas em contato com pessoas que não são do seu círculo mais próximo de relações, de se envolver em processos de decisão, de se inteirar de informações, de interagir com pesquisadores na condição de experts, etc.” (GATTI, 2012. p. 71).

Sendo assim, para esta pesquisa, foi realizado um grupo focal que reuniu dois professores (André e Fernando) e duas professoras (Karina e eu, que também atuei como pesquisadora e mediadora da discussão) ${ }^{5}$. André tinha 30 anos na ocasião da geração de dados, é professor de língua espanhola e atuava no ensino fundamental e médio de uma escola estadual da rede pública. Karina tinha 28 anos, é professora de história e atuava no ensino fundamental de escolas municipais da rede pública. Fernando tinha 33 anos, é professor de matemática e atuava no ensino fundamental e

\footnotetext{
${ }^{5}$ Os nomes dos participantes são fictícios e escolhidos por eles.
} 
médio em uma escola estadual da rede pública. Eu tinha 30 anos, sou professora de língua inglesa e atuava no ensino superior de uma instituição de ensino federal.

A partir de um convite meu e da concordância dos participantes, o encontro ocorreu no mês de julho de 2013 na instituição de ensino onde trabalho na cidade de Nova Friburgo. Algumas questões sobre diversos assuntos relacionados à prática docente foram propostas por mim e a conversa se desenvolveu durante aproximadamente uma hora. Toda a interação foi gravada em áudio e posteriormente transcrita de acordo com as convenções propostas por Sacks et al. (1974) baseadas nos estudos da Análise da Conversa.

Para realizar a análise dos dados gerados neste grupo focal, selecionei passagens em que foi possível perceber posicionamentos e avaliações dos participantes em relação à sua prática docente. Foi considerado subsistema de Atitude do Sistema de Avaliatividade com as categorias Afeto, Julgamento e Apreciação a fim de entender as avaliações presentes no discurso e compreender como os participantes constroem sua prática profissional.

\section{ANÁLISE DE DADOS}

Inicio esta análise com o fragmento 1 a seguir, que se desenrola em um momento do grupo focal onde os participantes tematizavam uma questão fundamental de sua prática: o momento da avaliação dos alunos. No trecho específico, que conta com a fala de Fernando, o assunto eram as provas oficiais elaboradas para avaliar níveis de ensino, sua aplicação dentro das escolas e as implicações para o trabalho docente. Podemos compreender seu posicionamento diante de tais práticas se levarmos em consideração as avaliações presentes no seu discurso, reproduzido abaixo com os grifos ${ }^{6}$ indicativos das avaliações que serão explicadas em seguida.

\section{Fragmento 1}

\footnotetext{
${ }^{6}$ Nesta análise, utilizo a marcação em negrito para indicar Afeto, sombreado cinza para Julgamento e itálico para Apreciação.
} 


\begin{tabular}{|c|c|c|}
\hline $\begin{array}{l}193 \\
194 \\
195 \\
196 \\
197 \\
198 \\
199 \\
200 \\
201 \\
202 \\
203\end{array}$ & $\begin{array}{l}\text { são eles, }<\text { na verdade porque a gente ta } \\
\text { vendo coisas, pela pressão, né, assim, essa } \\
\text { cobrança, praticamente um AssÉDIo moral do } \\
\text { profissional, né de você ter que produzir } \\
\text { resultados pra direção sem ter estrutura } \\
\text { humana e física necessária, ter que } \\
\text { produzir resultados, é um assédio moral e } \\
\text { profissional, é quase uma tortura, né, é... } \\
\text { e, você precisa maquiar esses resultados e } \\
\text { colocar naqueles mapas lindos, naquele } \\
\text { mural cheio de gatos, né, enfim, então eu }\end{array}$ & $\begin{array}{l}\text { Julgamento } \\
\text { sanção } \\
\text { social } \\
\text { Afeto }\end{array}$ \\
\hline
\end{tabular}

Fernando descreve a atitude das entidades sistema de avaliação e direção da escola como uma 'assédio moral e profissional', conduta considerada criminosa sujeita a penas previstas em lei, de modo que a escolha por comparar a situação constrangedora de produzir resultados que não existem a tal crime configura um Julgamento do tipo sanção social. O assédio moral ou profissional ocorre quando o trabalhador é exposto a condições humilhantes ao exercer suas funções por pessoas com as quais mantém relações assimétricas de poder, isto é, a agressão provém de profissionais com um nível hierárquico superior dentro da instituição. Em um caso de assédio, a vítima normalmente se submete às ofensas por medo de perder o emprego, benefícios, cargos ou até mesmo de ser ridicularizado ou excluído no ambiente de trabalho.

Sendo assim, acredito que o participante Fernando utiliza um conceito com uma forte carga social para caracterizar as situações a que estão submetidos os professores diante do atual sistema oficial de avaliação. Nesse caso, a Avaliação de Fernando está concentrada em um comportamento que ele julga negativamente e por esse motivo classificamos sua atitude como um Julgamento de sanção social. No entanto, ao observarmos a imagem construída por todo o seu enunciado, veremos que o participante se sente afetado emocionalmente pelo que ele define, inclusive com ênfase em sua fala, como 'assédio moral e profissional', já que tal conduta gera uma 'pressão' e uma 'tortura' sobre os professores, além de obrigá-los a forjar resultados que não correspondem à realidade. Portanto, embora não exista a presença explícita do foco no participante ou de sua reação emocional, como tradicionalmente encontramos em casos da categoria do Afeto, compreendo que todo o trecho envolvido pela linha neste fragmento é permeado por respostas emocionais de Fernando diante das situações que ele descreve. De acordo com Martin \& White (2005), as variáveis Julgamento e Apreciação do sistema de Atitude estão envolvidas pelo Afeto, pois ambos lidam com sentimentos institucionalizados. 
Para sintetizar o posicionamento de Fernando neste trecho, é possível afirmar que o participante critica fortemente a regulação do trabalho docente para que se possa compor um cenário de educação positivo por meio de uma roupagem calcada em números e evidências estatísticas. Fernando demonstra ainda como se sente afetado por estas condutas e indica como elas podem influenciar em sua prática profissional.

Dando prosseguimento à análise dos dados, identifico o fragmento 2 a seguir. Trata-se de uma interação entre André, Fernando e $\mathrm{eu}^{7}$ na qual os participantes constroem seu posicionamento no que tange a ser ou não profissional da educação e sobre falta de motivação característica dos que atuam nessa área. No fragmento em questão estão esquematizados os recursos do sistema de Atitude utilizados pelos participantes para construírem seu posicionamento diante do assunto ${ }^{8}$.

\section{Fragmento 2}

\begin{tabular}{|c|c|c|}
\hline $\begin{array}{l}1331 \\
1332 \\
1333\end{array}$ & $\begin{array}{l}\text { querer trabalhar com educação? }{ }^{\circ} \text { né? }{ }^{\circ} \text { hoje, } \\
\text { se eu pudesse escolher, eu jamais } \\
\text { trabalharia com educação, jamais. }\end{array}$ & Afeto \\
\hline 1334 & eu sempre trabalharia com educação & Afeto \\
\hline 1335 & [eu gosto, mas...] & Afeto \\
\hline 1336 & [ainda que ganhasse] um salário bem menor. & Afeto \\
\hline 1337 & você se sente desmotivado? & \\
\hline $\begin{array}{l}1338 \\
1339 \\
1340 \\
1341\end{array}$ & $\begin{array}{l}\text { totalmente, completamente, cara, você tá } \\
\text { numa via, né, com cinco faixas, você tá na } \\
\text { contramão, cara, tá todo mundo vindo de } \\
\text { frente e vc fica ( ) }\end{array}$ & Afeto \\
\hline 1342 & isso é muito fácil mudar. & $\begin{array}{l}\text { Apreciação } \\
\text { reação } \\
\text { impacto }\end{array}$ \\
\hline 1343 & vocês também [se sentem] desmotivados? & \\
\hline $\begin{array}{l}1344 \\
1345 \\
1346 \\
1347 \\
1348 \\
1349 \\
1350 \\
1351\end{array}$ & $\begin{array}{l}\text { [eu acho.] é: não, eu ainda to } \\
\text { numa realidade boa, que eu considero boa e } \\
\text { ainda que eu ganhasse metade do meu } \\
\text { salário, eu seria professor, porque eu } \\
\text { aprendi que quero me dedicar a isso, né, } \\
\text { então, é isso, eu não tô colocando aí a:s } \\
\text { questões financeiras acima, como deveria. } \\
\text { não estou, por uma questão pessoal. }\end{array}$ & $\begin{array}{l}\text { Apreciação } \\
\text { reação } \\
\text { qualidade } \\
\text { Afeto }\end{array}$ \\
\hline
\end{tabular}

Como se pode notar pelos trechos destacados no fragmento 2, os participantes Fernando e André se posicionam primordialmente por meio do Afeto para relatarem

\footnotetext{
${ }^{7}$ Os nomes foram suprimidos do fragmento por questões de espaço. Os nove turnos têm a seguinte ordenação: Fernando, André, Fernando, André, Suzana, Fernando, André, Suzana, André.

${ }^{8}$ No fragmento 2 os elementos modalizadores têm papel de destaque na construção do posicionamento. No entanto, sua análise minuciosa foge ao escopo deste trabalho, de modo que tais recursos serão mencionados apenas brevemente.
} 
sua relação emocional com a profissão e como se sentem enquanto professores. Segundo Martin (2001), a categoria do Afeto é explicitamente subjetiva e encontra-se na consciência de um participante humano, que é o centro da avaliação, diferentemente das outras duas categorias (Julgamento e Apreciação), onde o foco é a entidade avaliada. Sendo assim, quando os valores afetivos correspondem às respostas e estados emocionais dos autores, eles personalizam o texto, colocando em primeiro plano não só o papel individual do falante/escritor como também seu posicionamento avaliativo (Martin, 2001).

Nesse sentido, o que é destacado no posicionamento de Fernando pelo uso do Afeto que permeia seus enunciados é a sua grande desmotivação com a profissão, identificada na construção "totalmente, completamente desmotivado", onde os itens modalizadores sublinhados aqui por estarem enfatizados na sua fala intensificam a força da declaração. Esse sentimento de Fernando ocorre a despeito do seu envolvimento afetivo com a profissão, como se pode notar em "eu gosto, mas".

Além disso, observamos também o que podemos entender como um certo arrependimento por parte do participante por entrar na profissão docente, retratado em "hoje, se eu pudesse escolher, eu jamais trabalharia com educação, jamais". Nessa construção, Fernando impõe uma forte carga negativa na sua inclinação a ser professor através do advérbio 'jamais', enfatizado e repetido em seu discurso. Sendo assim, Fernando constrói seu posicionamento baseado em um Afeto negativo autoral, assumindo responsabilidade sobre o que foi dito e esboçando uma visão negativa sobre a atual situação de sua profissão. A ênfase nos itens 'totalmente', 'completamente' e 'jamais', bem como a repetição deste último atuam construindo convicção de seu posicionamento e desabafo de uma questão que afeta o participante emocionalmente.

A desmotivação que Fernando relata também pode ser associada a um certo cansaço de estar sempre lutando em vão, o que pode ser observado quando Fernando declara "você tá numa via, né, com cinco faixas, você tá na contramão". Entendo que nesse momento, o participante avalia em termos afetivos o sistema educacional, demonstrando como se sente em relação a ele e sinalizando os direcionamentos opostos do caminho da educação e daquele trilhado pelos professores. A expressão utilizada e o Afeto que ela veicula constroem o sentido de esforço sem recompensa, de remar contra a maré em um sistema com poucas perspectivas de mudança.

Para resumir o posicionamento de Fernando, temos que, em meio à situação precária da educação do país, nem mesmo o seu gosto pela profíssão o impulsionaria a 
segui-la, indicando que os fatores circunstanciais são mais fortes do que o apelo emocional da carreira. Soma-se a isso a ideia de que os profissionais lutam e enfrentam as adversidades impostas pela profissão, o que, todavia, parece não ter resultados.

Já no caso de André, o que o uso do Afeto em seu discurso traz à tona é a sua vontade de permanecer sempre nessa carreira, mesmo se ele estivesse em condições desfavoráveis, o que, segundo ele, não é o caso. André demonstra tal posicionamento nas linhas 1334, 1336, 1346 e 1347 reforçando sua inclinação em ser professor em quaisquer circunstâncias. Nas linhas mencionadas, o participante enfatiza, sobretudo, o aspecto financeiro por acreditar que esse seria um fator decisivo na escolha das pessoas pela profissão docente, indicando, por meio da expressão 'como deveria', na linha 1350, que essa é a postura mais natural e correta. No entanto, André deixa claro que não fez sua escolha pela profissão baseado em um possível retorno financeiro, mas por 'uma questão pessoal' e por ter aprendido que queria 'se dedicar a isso', fazendo sobressair um ponto de vista emocional e não racional. Essa emoção é construída no posicionamento de André em termos de Afeto positivo autoral onde o participante delineia uma visão positiva da profissão. Vale lembrar que o participante relata que atua em um ambiente cuja qualidade é apreciada positivamente por ele nas linhas 1344 e 1345.

Finalmente, reproduzo abaixo o fragmento 3 com a fala da participante Karina, que tematiza sua relação com a profissão.

\section{Fragmento 3}

\begin{tabular}{|l|l|l|l|}
\hline 1405 & sei lá, virei professora de história, e: & \\
1406 & nunca me senti tão bem, assim, não vou & \\
1407 & dizer que, eu me sinto desmotivada sim, & Afeto \\
1408 & quando eu me deparo com todas essas & \\
1409 & situações, eu me sinto desmotivada, mas por & \\
1410 & outro lado, não, não consigo pensar em & Apreciação \\
1411 & outro espaço de trabalho que se adeque mais & Composição \\
1412 & ao meu jeito de ser. eu me sinto, assim, & \\
1413 & satisfeita, é com o meu espaço de & Afeto + \\
1414 & trabalho, não me sinto satisfeita com as & Apreciação \\
1415 & situações, com os problemas... & \\
\hline
\end{tabular}

Neste trecho, Karina constrói seu posicionamento diante da sua prática em termos afetivos, indicando como está envolvida emocionalmente com sua profissão. No discurso de Karina, a questão emocional aparece de maneira positiva, se levarmos em consideração o trabalho docente em si e tudo o que ele representa, e de maneira 
negativa, se observarmos a insatisfação da participante diante dos problemas relacionados à profissão. Nesse sentido, paralelamente ao posicionamento afetivo, notase ainda uma Apreciação do trabalho docente como adequado à personalidade da participante bem como uma Apreciação negativa das situações que permeiam sua prática.

Nos três fragmentos analisados para esta pesquisa, é possível identificar, por meio da análise do discurso dos professores participantes, um posicionamento fundamentalmente afetivo em relação à sua prática profissional, de maneira que todos parecem estar envolvidos emocionalmente com seu trabalho. De acordo com Martin \& White (2005), o Afeto configura-se na expressão de sentimentos do falante, na qual ele indica como responde emocionalmente a um fenômeno bem como convida seu interlocutor a compartilhar de seu posicionamento. Sendo assim, além de escolher a inclinação emocional para construir sua prática profissional, os participantes também reivindicam uma solidariedade de seus pares para com seus sentimentos. Esta escolha e tentativa de sensibilização do outro pode estar relacionada ao entendimento da docência como uma atividade dimensionada pela interação humana e, portanto, pela questão afetiva, conforme apontado por Tardif \& Lessard (2013).

Secundariamente, observa-se também no posicionamento dos professores, o Julgamento negativo de algumas práticas condenáveis que ocorrem no contexto escolar, a Apreciação negativa da realidade educacional e a Apreciação positiva da profissão em si. Todas essas construções também demonstram afetar os participantes emocionalmente.

\section{CONSIDERAÇÕES FINAIS}

Este trabalho se propôs a compreender os posicionamentos docentes em relação à sua prática profissional. Tangenciado pelos princípios da LA, que atualmente investe na interdisciplinaridade e no papel social da pesquisa, o estudo articulou perspectivas teóricas sobre o trabalho docente com a visão de linguagem advinda da LSF e do SA para analisar o discurso dos professores participantes, agentes que de fato vivem a realidade do magistério.

Posto de maneira mais específica, os estudos educacionais sobre o trabalho docente contribuíram no sentido de orientar algumas das escolhas teóricometodológicas. Primeiramente, as análises sobre a docência devem partir do olhar para 
o processo e para a situação prática de trabalho dessas pessoas. Além disso, ouvir a voz dos atores principais deste movimento é uma maneira de entendê-los como teorizadores, praticantes e, em última análise, agentes capazes de deliberar sobre questões educacionais baseados em sua experiência imediata.

Tendo em vista que a profissão docente prevê a interação humana como condição de trabalho bem como a linguagem como mediadora das relações que ali se desenvolvem, entende-se que a compreensão dos posicionamentos dos professores deve passar por uma análise de seus discursos. Para tanto, a LSF e o SA contribuem na medida em que oferecem uma sistematização dos recursos disponíveis na língua para que as pessoas avaliem e se posicionem. Sendo assim, os estudos educacionais sobre o trabalho docente norteiam a opção por escutar professores e analisar seus discursos enquanto que a LSF e o SA circunscrevem a visão de linguagem para que essa análise esteja baseada em um sistema linguisticamente palpável.

As contribuições desta pesquisa são a compreensão do trabalho docente a partir dos sistemas concretos onde atuam e a possibilidade de construir conhecimentos balizados por visões tradicionalmente marginalizadas, ou, em outras palavras, a elaboração de um panorama sobre o trabalho docente que efetivamente se delineie a partir de suas práticas e suas falas e não a partir de estruturas dominantes. Ressalta-se ainda, a utilização da LSF e do SA para analisar dados em língua portuguesa, aumentando a visibilidade dessas perspectivas no Brasil e agregando conhecimentos ao modelo em outros domínios discursivos.

\section{REFERÊNCIAS}

BARBOUR, R. Grupos Focais. Porto Alegre: Artmed, 2009.

BARROSO, S. C. Tematização e Representação da prática docente: análise sistêmico-funcional da construção discursiva da profissão e da identidade do professor de inglês como língua estrangeira. Dissertação de Mestrado, PUC-Rio, 2009.

BARROSO AZEVEDO, S. C. A construção discursiva de posicionamentos sobre avaliação educacional: um estudo sistêmico-funcional com professores da educação básica. Tese de Doutorado, PUC-Rio, 2015.

BUTT, D. et al. Using Functional Grammmar: An Explorer's Guide. Sydney: Macquarie University, 1998. 
DIRECT (PUC-SP) et. al. Termos da gramática sistêmico-funcional em português aprovados para utilização pelos participantes da lista de discussão gsfemportugues@egroups.com. Disponível em: http://ww3.fl.ul.pt/pessoais/cgouveia/ docs\%5CTermosGSF.pdf. Acesso em: 10 set. 2012.

GATTI, B. A. Grupo focal na pesquisa em Ciências Sociais e Humanas. Brasília: Liber Livro Editora, 2012.

GIROUX, H. A. Os professores como intelectuais: rumo a uma pedagogia crítica da aprendizagem. Porto Alegre: Artes Médicas, 1997.

HALLIDAY, M. A. K.; HASAN, R. Language, context, and text: aspects of language in a social-semiotic perspective. Oxford: Oxford University Press, 1989.

HALLIDAY, M. A. K. An Introduction to Functional Grammar. London: Arnold, 1994.

HALLIDAY, M. A. K.; MATTHIESSEN, C. An Introduction to Functional Grammar. London: Arnold, 2004.

KRUEGER, R. A. \& CASEY, M. A. Focus groups: A practical guide for applied research. California: Sage Publications, 2000.

LINCOLN, Y. S. \& DENZIN, N. K. O sétimo momento: deixando o passado para trás. In: DENZIN, N. K. \& LINCOLN, Y. S. (Orgs.). O planejamento da pesquisa qualitativa. Porto Alegre: Artmed, 2006. p. 389-406.

MARTIN, J. R. Analysing Genre: Functional Parameters. In: CHRISTIE, F. \& MARTIN, J.R. Genres and Institutions: Social Processes in the Workplace and School. London: Cassel, 1997. p. 230-256.

MARTIN, J. R. Beyond Exchange: APPRAISAL Systems in English. In: HOUSTON, S. \& THOMPSON, G. (Eds.). Evaluation in Text. Oxford: Oxford University Press, 2001. p. 142-175.

MARTIN, J. R. \& ROSE, D. Working with Discourse - Meaning Beyond de Clause. New York: Continuum, 2003.

MARTIN, J. R. \& WHITE, P. R. R. The language of evaluation: appraisal in English. New York: Palgrave Macmillan, 2005.

MOITA LOPES, L. P. (Org.). Por uma Linguística Aplicada Indisciplinar. São Paulo: Parábola Editorial, 2006.

MOITA LOPES, L. P. (Org.). Linguística Aplicada na modernidade recente. São Paulo: Parábola Editorial, 2013.

SACKS, H. et al. A Simplest Systematics for the organization of Turn-Taking for Conversation. Language, 50, p. 696-735. 1974. 
TARDIF, M. et al. Formation des maîtres et contextes sociaux: perspectives internationales. Paris: Presses Universitaires de France, 1998.

TARDIF, M. \& LESSARD, C. O Trabalho Docente. Elementos para uma teoria da docência como profissão de interações humanas. Petrópolis: Vozes, 2013.

WHITE, J. Appraisal: an overview. 2001. Disponível em www.grammatics.com. Acesso em: 20 out 2012.

\begin{abstract}
A AUTORA
Suzana de Carvalho Barroso Azevedo possui Graduação em Letras (PortuguêsInglês) pela Universidade Federal do Rio de Janeiro (UFRJ) e Especialização em Ensino de Inglês pela Universidade Federal de Minas Gerais (UFMG). Cursou Mestrado e Doutorado em Estudos da Linguagem na Pontifícia Universidade Católica do Rio de Janeiro (PUC-Rio). Atua como professora de língua inglesa há 15 anos e faz parte do quadro permanente do CEFET/RJ, campus Nova Friburgo, como professora de língua inglesa e portuguesa.
\end{abstract}

E-mail: suzanabarroso@gmail.com 